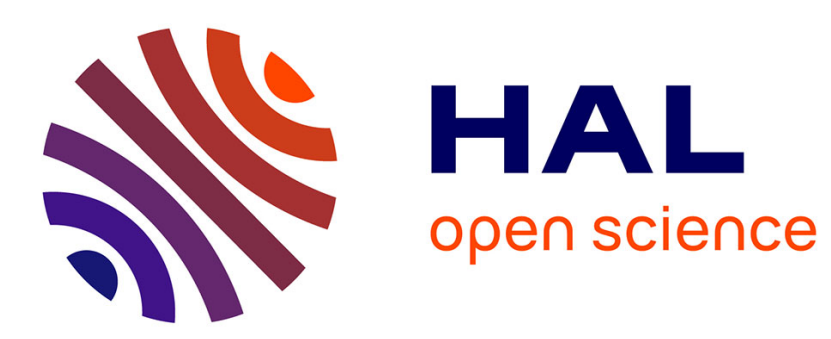

\title{
Taste for variety and endogenous fluctuations in a monopolistic competition model
}

Thomas Seegmuller

\section{To cite this version:}

Thomas Seegmuller. Taste for variety and endogenous fluctuations in a monopolistic competition model. 2007. halshs-00143424

\section{HAL Id: halshs-00143424 \\ https://shs.hal.science/halshs-00143424}

Submitted on 25 Apr 2007

HAL is a multi-disciplinary open access archive for the deposit and dissemination of scientific research documents, whether they are published or not. The documents may come from teaching and research institutions in France or abroad, or from public or private research centers.
L'archive ouverte pluridisciplinaire HAL, est destinée au dépôt et à la diffusion de documents scientifiques de niveau recherche, publiés ou non, émanant des établissements d'enseignement et de recherche français ou étrangers, des laboratoires publics ou privés. 


\section{Documents de Travail du Centre d'Economie de la Sorbonne}

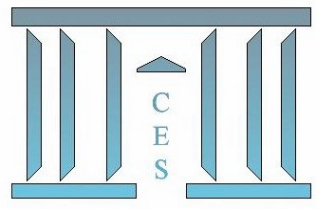

Taste for Variety and Endogenous Fluctuations in a Monopolistic Competition Model

Thomas SEEGMULLER

2007.04 


\section{Taste for Variety and Endogenous Fluctuations in a Monopolistic Competition Model}

Thomas Seegmuller

CNRS and Centre d'Economie de la Sorbonne,

Paris School of Economics, Université Paris 1,

106-112 Boulevard de l'Hôpital 75647 Paris Cedex 13, France.

Tel: (33) 144078199

Fax: (33) 144078231

E-mail: seegmu@univ-paris1.fr 


\begin{abstract}
In past years, imperfect competition has been introduced in several dynamic models to show how mark-up variability, increasing returns (decreasing marginal cost), and monopoly profits affect the occurrence of endogenous fluctuations. In this paper, we focus on another possible feature of imperfectly competitive economies: consumers' taste for variety due to endogenous product diversity. Introducing monopolistic competition (Dixit and Stiglitz (1977), Benassy (1996)) in an overlapping generations model where consumers have taste for variety, we show that local indeterminacy can occur under the three following conditions: a high substitution between capital and labor, increasing returns arbitrarily small and a not too elastic labor supply. The key mechanism for this result is based on the fact that, due to taste for variety, the aggregate price decreases with the pro-cyclical product diversity, which has a direct influence on the real wage and the real interest rate.
\end{abstract}

Keywords: Endogenous fluctuations, taste for variety, imperfect competition.

\title{
Résumé
}

Dans les années passées, la concurrence imparfaite a été introduite dans des modèles dynamiques pour montrer comment la variabilité du taux de marge, les rendements croissants (coût marginal décroissant), et les profits de monopole affectent l'apparition de fluctuations endogènes. Dans ce papier, nous nous intéressons à une autre caractéristique des économies imparfaitement concurrentielles : le goût pour la variété dû à la diversité endogène des produits. Introduisant de la concurrence monopolistique (Dixit et Stiglitz (1977), Benassy (1996)) dans un modèle à générations imbriquées dans lequel les consommateurs ont du goût pour la variété, nous montrons que de l'indétermination locale peut apparaître sous les trois conditions suivantes : une substitution entre le capital et le travail élevée, des rendements croissants arbitrairement faibles et une offre de travail pas trop fortement élastique. Le mécanisme clé pour ce résultat repose sur le fait que, dû au goût pour la variété, le prix agrégé décroît avec la diversité pro-cyclique des produits, ce qui influence directement le salaire et le taux d'intérêt réels.

Mots-clés: Fluctuations endogènes, goût pour la variété, concurrence imparfaite.

JEL classification: C62, D43, E32. 


\section{Introduction}

Imperfect competition on the product market has been introduced in macrodynamic models to analyze the influence of increasing returns, or equivalently a decreasing marginal cost, mark-up variability and monopoly profits on the emergence of endogenous fluctuations, i.e. on the existence of deterministic cycles and fluctuations due to self-fulfilling prophecies. In this paper, we focus on another feature of imperfectly competitive economies, that is, consumers' taste for variety due to the variable product diversity, and study how this affects dynamics. We show that this creates a new mechanism because, due to taste for variety, the aggregate price decreases with the pro-cyclical product diversity, which introduces a modification of the real wage and the real interest rate. Moreover, considering even a small degree of taste for variety, local indeterminacy becomes compatible with three conditions that have an empirical support: a high elasticity of capital-labor substitution, increasing returns arbitrarily small and a not too elastic labor supply.

The overlapping generations model is one of the most commonly used framework to analyze the link between endogenous fluctuations and capitallabor substitution. In a perfectly competitive economy populated by twoperiod lived agents, Reichlin (1986) shows that endogenous cycles require a sufficiently weak elasticity of capital-labor substitution. The framework considered is based on a constant returns technology and on consumers who supply labor at the first period of life and consume only at the second one. ${ }^{1}$ The condition obtained by Reichlin (1986) has been criticized because it is not satisfied by recent estimates finding greater values for this elasticity (Duffy and Papageorgiou (2000)). This last remark provides also a justification for the introduction of imperfect competition and the analysis of its role on the dynamic properties of the economy.

Assuming Cournot competition, internal increasing returns due to a decreasing marginal cost and free entry, Lloyd-Braga (1995) proves that endogenous fluctuations can emerge if the degree of capital-labor substitution is not too low. More recently, Cazzavillan (2001) obtains the same sort of results introducing productive capital externalities in the framework developed by Reichlin (1986). ${ }^{2}$ This author further shows that endogenous fluctuations can occur for externalities arbitrarily small, if the labor supply is sufficiently

\footnotetext{
${ }^{1}$ As usually, Reichlin (1986) also assumes intertemporal gross substitutability. Note however that when this condition is violated, endogenous fluctuations can occur for higher degrees of capital-labor substitution. See Nourry and Venditti (2006).

${ }^{2}$ Note that the specification of imperfect competition considered by Lloyd-Braga (1995) and the model with productive externalities are quite similar. See Benhabib and Farmer (1994) and Cazzavillan, Lloyd-Braga, and Pintus (1998).
} 
elastic with respect to the real wage. Extending the Reichlin (1986) framework to consumption in both periods and labor externalities, Lloyd-Braga, Nourry, and Venditti (2006) also establish that, under a low level of increasing returns, indeterminacy appears for a high capital-labor substitution and a sufficiently elastic labor supply. ${ }^{3}$ Note that, in all these contributions, the results come from the fact that the marginal productivities are altered by the degree of increasing returns.

Focusing on strategic interactions between producers under a pro-cyclical number of firms, Dos Santos Ferreira and Lloyd-Braga (2005) and Seegmuller (2004) consider the case of a counter-cyclical mark-up. Both contributions show that endogenous fluctuations can emerge when the elasticity of capitallabor substitution is high. In the first paper, the authors assume Cournot competition while in the second one, a monopolistic competition model is used. Note that when increasing returns to scale, due to the existence of a fixed cost, are close to the constant ones, Dos Santos Ferreira and LloydBraga (2005) show that indeterminacy requires a highly elastic labor supply, while Seegmuller (2004) restricts his analysis to the case of an infinitely elastic labor supply. In these two papers, the key element is the existence of a variable gap between the real prices of production factors and the marginal productivities explained by the counter-cyclical mark-up factor.

Recently, Seegmuller (2005) analyzes the role of monopoly profits on the stability properties of an overlapping generations economy. ${ }^{4}$ He shows that indeterminacy requires a less elastic labor supply but a weaker substitution between capital and labor than under perfect competition. In this framework, imperfect competition affects the dynamics because the distribution of monopoly profits modifies the lifetime income of consumers.

In this paper, we focus on another possible feature of imperfectly competitive models. Introducing monopolistic competition with free entry and increasing returns due to a fixed cost in an overlapping generations economy with capital accumulation, we study the influence of taste for variety on local indeterminacy and the occurrence of bifurcations. ${ }^{5}$ Using the Dixit and Stiglitz (1977) specification, the model is characterized by a constant mark-up and the product diversity is endogenous and pro-cyclical. Follow-

\footnotetext{
${ }^{3}$ In this paper, a low enough ratio between savings and labor income is also assumed, which is a relevant configuration.

${ }^{4} \mathrm{He}$ extends the work of Jacobsen (2000) to an economy with capital accumulation, but he considers the labor market as perfectly competitive.

${ }^{5}$ Jacobsen (1998) studies the influence of taste for variety on the emergence of endogenous fluctuations in a monetary overlapping generations model. Since he does not consider capital accumulation, he cannot analyze the link between capital-labor substitution and endogenous fluctuations, as it is done in this paper.
} 
ing Benassy (1996), taste for variety represents the marginal utility gain of consuming one unit of an additional differentiated good and implies that an increase of product diversity decreases the aggregate price at the symmetric equilibrium. Therefore, the real wage and the real interest rate increase with the pro-cyclical number of producers because of taste for variety. In this paper, we analyze the dynamic implications of this feature of imperfectly competitive economies. We show that local indeterminacy occurs for all degree of capital-labor substitution greater than one half, arbitrarily small increasing returns and a labor supply not too elastic with respect to the real wage.

To obtain this main result, we first establish the existence of a steady state. Then, using the geometrical method developed by Grandmont, Pintus, and de Vilder (1998), we study its local stability and the occurrence of local bifurcations. We begin by shortly analyze the case without taste for variety. We prove that endogenous fluctuations can emerge only if the elasticity of capital-labor substitution is smaller than the capital share in income, which is lower than one half. Therefore, we obtain the same results than Reichlin (1986) under perfect competition. This is not so surprising since the level of increasing returns and the mark-up have no influence on the dynamics. ${ }^{6}$

In a second step, we assume that consumers have taste for variety, but we restrict our analysis to the case where its degree is not too large. As before, local indeterminacy and endogenous deterministic cycles can emerge if capital and labor are sufficiently weak substitutes. However, more interestingly, the steady state can also be locally indeterminate for larger values of the elasticity of capital-labor substitution, i.e. as soon as this elasticity takes values greater than one half. This means that when there is taste for variety, fluctuations due to self-fulfilling prophecies occur for values of the substitution between capital and labor in accordance with empirical studies (see Duffy and Papageorgiou (2000)).

Moreover, since the level of mark-up and increasing returns, i.e. the fixed cost, have no influence on the dynamics, imperfect competition affects the stability properties of the economy only through consumers' taste for variety. Indeed, as we have already mentioned, the mechanism that promotes indeterminacy goes through the aggregate price that decreases with the procyclical product diversity. Therefore, business formation positively affects the real wage and the real interest rate, with a magnitude depending on the degree of taste for variety only. This also means that our results are relevant for increasing returns arbitrarily close to the constant ones, which seems to

\footnotetext{
${ }^{6}$ Indeed, the level of the fixed cost and the mark-up factor do not enter the Jacobian matrix.
} 
be in accordance with recent empirical works (see Basu and Fernald (1995), Basu and Fernald (1997), Burnside (1996)).

Finally, it is also interesting to remark that the occurrence of local indeterminacy for a high degree of substitution between capital and labor and arbitrarily small increasing returns to scale does not require an infinitely elastic labor supply. This feature of our results also seems to be in accordance with empirical works (see Pencavel (1986), Killingsworth and Heckman (1986), Blundell and Macurdy (1999)). Note however that this is only relevant for a degree of taste for variety not arbitrarily small.

This paper is organized as follows. In the next section, we present the model. In Section 3, we establish the existence of a steady state. We study local dynamics in Section 4 and conclude in Section 5. Some technical details are given in the Appendix.

\section{The Model}

In this section, we present the model and determine the intertemporal equilibrium. We begin by consumers' behavior.

\subsection{Consumers}

We consider an overlapping generations model with discrete time, $t=1,2, \ldots$, $+\infty$, and perfect foresight. The initial capital stock $K_{0}>0$ is given. At each period, there is a continuum of identical consumers, living two periods. The size of each generation is normalized to one. At the first period, each consumer chooses to supply labor $L_{t}$, which is remunerated at the wage rate $w_{t}$. He saves his income through the purchase of productive capital $K_{t}$ that firms use for production in the following period. When he is old, he spends his savings, remunerated at the interest factor $r_{t+1}$, to consume final goods $\left(C_{t+1}\right) \cdot{ }^{7}$ Preferences being additively separable between consumption and leisure, the utility function can be written:

$$
U\left(C_{t+1} / B\right)-V\left(L_{t}\right)
$$

where $B>0$ is a scaling parameter. The utility function (1) satisfies the following assumption:

\footnotetext{
${ }^{7}$ Capital totally depreciates after one period of use.
} 
Assumption 1 The functions $U(C / B)$ and $V(L)$ are continuous for all $C \geq 0$ and $0 \leq L \leq \bar{L}$, where the labor endowment $\bar{L}>1$ may be finite or infinite. ${ }^{8}$ They are $\mathcal{C}^{n}$ for $C>0,0<L<\bar{L}$ and n large enough, with $U^{\prime}(x)>0$, $U^{\prime \prime}(x)<0, V^{\prime}(L)>0$ and $V^{\prime \prime}(L)>0$. Moreover, $\lim _{L \rightarrow \bar{L}} V^{\prime}(L)=+\infty$ and consumption and leisure are gross substitutes, i.e., $-x U^{\prime \prime}(x) / U^{\prime}(x)<1$.

In equation (1), $C_{t+1}$ is a single composite good represented by the aggregate of varieties:

$$
C_{t+1}=N_{t+1}^{1+\beta}\left[\frac{1}{N_{t+1}} \int_{0}^{N_{t+1}} c_{i t+1}^{\frac{\epsilon-1}{\epsilon}} d i\right]^{\frac{\epsilon}{\epsilon-1}} \equiv W\left(\left(c_{i t+1}\right)_{i \in\left[1, N_{t+1}\right]}\right)
$$

where $\beta \geq 0$ and $\epsilon>1 .^{9}$ Following Benassy (1996), we define a function $t(N)$ which represents the gain from consuming one unit of $N$ differentiated goods instead of consuming $N$ units of a single variety. From equation (2), $t(N)$ is defined by $W(1) / N=N^{\beta}$ and taste for variety is defined by the elasticity of $t(N)$ :

$$
\tau(N) \equiv \frac{N t^{\prime}(N)}{t(N)}=\beta
$$

Therefore, there is no taste for variety when $\beta=0$ while consumers have taste for variety when $\beta>0$. We can also remark that with the specification we use, taste for variety does not depend on the parameter $\epsilon$ which will determine the level of mark-up.

Each consumer maximizes his utility function (1) subject to (2) and the two budget constraints:

$$
\begin{gathered}
P_{t} K_{t}=w_{t} L_{t} \\
P_{t+1} C_{t+1}=r_{t+1} K_{t}
\end{gathered}
$$

where $P_{t}=N_{t}^{-\beta}\left[\left(1 / N_{t}\right) \int_{0}^{N_{t}} p_{i t}^{1-\epsilon} d i\right]^{\frac{1}{1-\epsilon}}$ is the price of the composite good and $p_{i t}$ the price of variety $i$. First, he chooses his consumption of good $i$ :

$$
c_{i t+1}=N_{t+1}^{\beta(\epsilon-1)-1}\left(\frac{p_{i t+1}}{P_{t+1}}\right)^{-\epsilon} C_{t+1}
$$

\footnotetext{
${ }^{8}$ The labor endowment is assumed to be strictly greater than one to ensure that labor can take the value one at an equilibrium. See Section 3 for more details.

${ }^{9}$ This last assumption means that the differentiated goods are substitutes. Note that the aggregate of varieties (2) is similar to the one introduced in Benassy (1996) except that we use an integral instead of a discrete sum. This does not change the results, but implicitly underlines that the aggregate variables are taken as given by the producers when they maximize their profits (see Section 2.2). In the literature, aggregates of varieties with an integral sum have been used by several authors. See among others Ball and Romer (1991), Dos Santos Ferreira and Lloyd-Braga (2002), Rivard (1994), Seegmuller (2005) and Weder (2000).
} 
Secondly, he determines his intertemporal choice between consumption and leisure:

$$
\begin{gathered}
u\left(C_{t+1} / B\right)=v\left(L_{t}\right) \\
C_{t+1}=\rho_{t+1} \omega_{t} L_{t}
\end{gathered}
$$

where $u(x)=x U^{\prime}(x), v(L)=L V^{\prime}(L), \rho_{t+1}=r_{t+1} / P_{t+1}$ is the real interest factor and $\omega_{t}=w_{t} / P_{t}$ the real wage. Under Assumption 1, there exists a function $\gamma \equiv u^{-1} \circ v$, such that $C_{t+1} / B=\gamma\left(L_{t}\right)$. Since consumption and leisure are gross substitutes, $\varepsilon_{\gamma}(L) \equiv \gamma^{\prime}(L) L / \gamma(L)=[1+$ $\left.L V^{\prime \prime}(L) / V^{\prime}(L)\right] /\left[1+x U^{\prime \prime}(x) / U^{\prime}(x)\right]>1$, with $x=C / B$. This means that the labor supply increases with respect to the real wage, with an elasticity defined by $1 /\left(\varepsilon_{\gamma}(L)-1\right)>0$.

\section{$2.2 \quad$ Firms}

Following Dixit and Stiglitz (1977), there is monopolistic competition in the good market. Furthermore, entry and exit are free and a zero profit condition determines the number $N_{t}$ of active firms at period $t$. Each firm produces a single variety $i$ of output using the following technology:

$$
y_{i t}=A\left(f\left(a_{i t}\right) l_{i t}-\phi\right)
$$

where $A>0$ is a scaling parameter, $a_{i t}=k_{i t-1} / l_{i t}$ the capital-labor ratio, $l_{i t}$ $\left(k_{i t-1}\right)$ the labor (capital) used by firm $i$ and $\phi>0$ a fixed cost. We further assume:

Assumption 2 The intensive production function $f(a)$ is continuous for $a \geq 0$, positively valued and differentiable as many times as needed for $a>0$, with $f^{\prime}(a)>0$ and $f^{\prime \prime}(a)<0$.

This means that the marginal cost is constant and increasing returns are only due to the existence of the fixed $\operatorname{cost} \phi>0$.

Aggregate production $Y_{t} \equiv \int_{0}^{N_{t}} p_{i t} y_{i t} d i$ is shared between aggregate consumption and investment $I_{t}$, where $I_{t}=K_{t}$. Since demands for consumption and investment correspond to the same goods, we assume, as in several existing papers, that $I_{t}$ is defined by the same index of varieties than $C_{t}{ }^{10}$

\footnotetext{
${ }^{10}$ See for instance Cook (2001), Dos Santos Ferreira and Lloyd-Braga (2002), Kiyotaki (1988) or Weder (2000). A well-known exception can be found in Gali (1994) who explains mark-up variability by the difference in elasticities of substitution between varieties in aggregate consumption and investment. To further justify the introduction of the same index of variety for consumption and investment, note also that in this model, the investment goods are in fact bought by the consumer, at an amount corresponding to savings, and therefore aggregate capital, and are used to consume in the next period.
} 
i.e.

$$
I_{t}=N_{t}^{1+\beta}\left[\frac{1}{N_{t}} \int_{0}^{N_{t}} i_{i t}^{\frac{\epsilon-1}{\epsilon}} d i\right]^{\frac{\epsilon}{\epsilon-1}}
$$

where $i_{i t}$ represents investment demand in variety of good $i$ and is optimally determined by:

$$
i_{i t}=N_{t}^{\beta(\epsilon-1)-1}\left(\frac{p_{i t}}{P_{t}}\right)^{-\epsilon} I_{t}
$$

Therefore, the demand of a variety $i$ is defined by $d_{i t}=c_{i t}+i_{i t}$, where $c_{i t}$ and $i_{i t}$ are respectively given by (6) and (11), i.e.

$$
d_{i t}=N_{t}^{\beta(\epsilon-1)-1}\left(\frac{p_{i t}}{P_{t}}\right)^{-\epsilon}\left(C_{t}+I_{t}\right)
$$

Each producer maximizes its profits $p_{i t} y_{i t}-r_{t} k_{i t-1}-w_{t} l_{i t}$, facing the demand function (12). Since capital and labor markets are perfectly competitive, the first order conditions are given by:

$$
\begin{gathered}
p_{i t}(1-1 / \epsilon) A f^{\prime}\left(a_{i t}\right)=r_{t} \\
p_{i t}(1-1 / \epsilon) A\left(f\left(a_{i t}\right)-a_{i t} f^{\prime}\left(a_{i t}\right)\right)=w_{t}
\end{gathered}
$$

At the symmetric equilibrium, $a_{i t}=a_{t}, k_{i t-1}=k_{t-1}, l_{i t}=l_{t}$ and $p_{i t}=p_{t}$ for all $i$. We deduce:

$$
\begin{gathered}
\rho_{t}=N_{t}^{\beta}(1-1 / \epsilon) A f^{\prime}\left(a_{t}\right) \equiv A \rho\left(a_{t}, N_{t}\right) \\
\omega_{t}=N_{t}^{\beta}(1-1 / \epsilon) A\left(f\left(a_{t}\right)-a_{t} f^{\prime}\left(a_{t}\right)\right) \equiv A \omega\left(a_{t}, N_{t}\right) \\
P_{t}=N_{t}^{-\beta} p_{t}
\end{gathered}
$$

From (15) and (16), we remark that since the elasticity of the demand of a variety $i$ with respect to the price is equal to $\epsilon$ (in absolute value), the markup factor $\epsilon /(\epsilon-1)$ is constant. We also notice that when there is no taste for variety $(\beta=0)$, the aggregate price $P_{t}$ is equal to $p_{t}$ at the symmetric equilibrium. On the other hand, when consumers have taste for variety $(\beta>0)$, the aggregate price $P_{t}$ decreases with the number of differentiated goods. This is why, in this last case, the real wage and the real interest rate increase with respect to $N_{t}$, which corresponds to the key element that drives the new results obtained in this paper.

The number of firms is determined by the usual zero profit condition. We obtain:

$$
f\left(a_{t}\right) l_{t} / \epsilon=\phi
$$


This free-entry condition also means that the production level of each firm is constant at equilibrium: $y_{t}=A\left(f\left(a_{t}\right) l_{t}-\phi\right)=A(\epsilon-1) \phi$.

Before determining the intertemporal equilibrium, it is useful to define the following relationships. First, we note the elasticity of the intensive production function $s(a) \equiv f^{\prime}(a) a / f(a) \in(0,1){ }^{11}$ Moreover, if we note $\sigma(a) \geq 0$ the elasticity of capital-labor substitution, $1 / \sigma(a)=d \ln (f(a)-$ $\left.a f^{\prime}(a)\right) / d \ln a-d \ln f^{\prime}(a) / d \ln a$. Since $d\left(f(a)-a f^{\prime}(a)\right) / d a=-a f^{\prime \prime}(a)$, we deduce that:

$$
\begin{gathered}
\frac{d \ln \left(f(a)-a f^{\prime}(a)\right)}{d \ln a}=\frac{s(a)}{\sigma(a)} \\
\frac{d \ln f^{\prime}(a)}{d \ln a}=-\frac{1-s(a)}{\sigma(a)}
\end{gathered}
$$

\subsection{Equilibrium}

At each period, aggregate capital is predetermined by the savings of the previous generation. At equilibrium, $K_{t-1}=N_{t} k_{t-1}$. Equilibrium in the labor market requires $L_{t}=N_{t} l_{t}$. Using this last equation, the free entry condition (18) and $L_{t}=K_{t-1} / a_{t}$, we obtain:

$$
N_{t}=\frac{f\left(a_{t}\right) K_{t-1}}{\epsilon \phi a_{t}} \equiv N\left(a_{t}, K_{t-1}\right)
$$

The product diversity is pro-cyclical. Indeed, equation (21) is equivalent to $N_{t}=Y_{t} /(A(\epsilon-1) \phi)$, where $Y_{t}=N_{t} y_{t}$.

Substituting (8), (15), (16) and (21) in equations (4) and (7), we have:

$$
\begin{gathered}
K_{t}=A \omega\left(a_{t}, N\left(a_{t}, K_{t-1}\right)\right) K_{t-1} / a_{t} \\
A^{2} \rho\left(a_{t+1}, N\left(a_{t+1}, K_{t}\right)\right) \omega\left(a_{t}, N\left(a_{t}, K_{t-1}\right)\right) / B=\gamma\left(K_{t-1} / a_{t}\right) /\left(K_{t-1} / a_{t}\right)
\end{gathered}
$$

Definition 1 An intertemporal equilibrium with perfect foresight is a sequence $\left(K_{t-1}, a_{t}\right) \in \mathbb{R}_{++}^{2}, t=1,2, \ldots, \infty$, such that (22) and (23) are satisfied, given the initial capital stock $K_{0}>0$.

Equations (22) and (23) rule the dynamics of the model and define a two dimensional dynamic system with one predetermined variable, aggregate capital $K_{t-1} \cdot{ }^{12}$

\footnotetext{
${ }^{11}$ We can notice that $s(a)$ represents the capital share in income when $\beta=0$. Indeed, substituting (18) into (15), we obtain $\rho_{t} k_{t-1}=s\left(a_{t}\right) y_{t}$ in this case.

${ }^{12}$ Note however that the capital used by an individual firm $k_{t-1}$ for the production at period $t$ is not predetermined. Indeed, using capital market equilibrium, we have $k_{t-1}=$ $K_{t-1} / N\left(a_{t}, K_{t-1}\right)$ which depends on the non-predetermined variable $a_{t}$, and therefore on expectations of future real interest rate.
} 


\section{Existence of a Steady State}

In this section we establish the existence of a steady state of the dynamic system (22)-(23). ${ }^{13}$ Our analysis will closely follow Cazzavillan, Lloyd-Braga, and Pintus (1998).

A steady state of the dynamic system (22)-(23) is a solution $(K, a)=$ $\left(K_{t-1}, a_{t}\right)$ for all $t$, such that:

$$
\begin{gathered}
A=a / \omega(a, N(a, K)) \\
u\left[\left(A^{2} / B\right) \rho(a, N(a, K)) \omega(a, N(a, K)) K / a\right]=v(K / a)
\end{gathered}
$$

We establish existence by proving that, under some conditions explicitly given in the next proposition, there exist unique strictly positive values of the two scaling parameters $A$ and $B$ ensuring that one steady state coincides with $(K, a)=(1,1)$. From equation $(24)$, we obtain a unique solution:

$$
A^{*}=1 / \omega(1, N(1,1))
$$

Substituting this expression in equation (25), we get:

$$
u[(1 / B) \rho(1, N(1,1)) / \omega(1, N(1,1))]=v(1)
$$

Since consumption and leisure are gross substitutes (Assumption 1), $u$ is decreasing in $B$. There exists a unique $B^{*}$ satisfying equation $(27)$ if and only if:

$$
\lim _{x \rightarrow 0} u(x)<v(1)<\lim _{x \rightarrow+\infty} u(x)
$$

This result is summarized in the following proposition:

Proposition 1 If inequality (28) and Assumptions 1 and 2 are satisfied, $(K, a)=(1,1)$ is a stationary solution of the dynamic system (22)-(23) if and only if $A^{*}$ and $B^{*}$ are the unique solutions of (26) and (27).

\section{Local Dynamics and Bifurcation Analysis}

In this section we analyze the influence of taste for variety on the emergence of endogenous fluctuations, i.e. on local indeterminacy and deterministic cycles. We discuss our results in function of four parameters: the degree of taste for variety, the elasticity of labor supply, the substitution between

\footnotetext{
${ }^{13}$ For sake of brevity, we do not analyze uniqueness versus multiplicity of stationary solutions.
} 
capital and labor, and the level of increasing returns. To make easier the comparison, we consider first the case without taste for variety. We show that, as in the perfectly competitive model developed by Reichlin (1986) with consumption only in the second period of life, endogenous fluctuations require weak values of the elasticity of capital-labor substitution. ${ }^{14}$ However, with taste for variety, local indeterminacy can occur for higher values of the elasticity of capital-labor substitution, a not too elastic labor supply and returns to scale arbitrarily close to the constant ones. As we will see later, these findings are obtained assuming a not too great degree of taste for variety.

To pursue this analysis, we linearize the dynamic system (22)-(23) in the neighborhood of the steady state defined in Proposition 1 . We get the following proposition:

Proposition 2 Let $s \equiv s(1), \sigma \equiv \sigma(1)$ and $\varepsilon_{\gamma} \equiv \varepsilon_{\gamma}(1)$. Under Assumptions 1 and 2, the characteristic polynomial is defined by $Q(\lambda) \equiv \lambda^{2}-T \lambda+D=0$, where:

$$
\begin{gathered}
D=D_{1} \varepsilon_{\gamma}, \text { with } D_{1}=\frac{s}{1-s} \\
T=\frac{\sigma}{(1-s)(\beta \sigma+1)}\left(\varepsilon_{\gamma}-1\right)+T_{1}, \\
\text { with } T_{1}=1+D_{1}+\frac{\beta(1-2 \sigma)}{(1-s)(\beta \sigma+1)}
\end{gathered}
$$

Proof. See the Appendix.

Following Grandmont, Pintus, and de Vilder (1998), we study the local stability of the steady state and the occurrence of bifurcations by analyzing the trace $T$ and the determinant $D$ (see Figures 1 and 2). One eigenvalue is equal to 1 on the line $(A C)(1-T+D=0)$. An eigenvalue is equal to -1 on the line $(A B)(1+T+D=0)$. On the segment $[B C]$, the two eigenvalues are complex conjugate and have modulus equal to $1(D=1$ and $|T|<2)$. Therefore, the steady state is a sink when $(T, D)$ is inside $(A B C)$. It is a source if $(T, D)$ is above $(A B),(A C)$ and $[B C]$ or below $(A B)$ and $(A C)$. In all other cases, it is a saddle.

Suppose now that $T$ and $D$ change when a parameter, called the bifurcation parameter, varies continuously. When the point $(T, D)$ intersects the line $(A C)$, a transcritical bifurcation generically occurs. When the point

\footnotetext{
${ }^{14}$ Note that, when there is perfect competition and consumption in both periods, indeterminacy can occur if the elasticity of capital-labor substitution is large enough, that is, greater than the capital share in total income. However, gross substitutability need to be violated. See Nourry and Venditti (2006) for more details.
} 
$(T, D)$ intersects the line $(A B)$, one gets a flip bifurcation, i.e. a cycle of period two. Finally when the point $(T, D)$ crosses the segment $[B C]$, one gets a Hopf bifurcation, i.e. an invariant closed curve appears around the steady state. ${ }^{15}$ Moreover since capital is a predetermined variable, the steady state is locally indeterminate if it is a sink. In this case, fluctuations driven by the volatility of expectations appear in the neighborhood of the steady state. Endogenous stochastic fluctuations can also emerge in the neighborhood of a cycle of period two if it is locally stable or in the neighborhood of an invariant closed curve if the Hopf bifurcation is supercritical. ${ }^{16}$

We now apply this method to our model. In what follows, we assume that the elasticity of the intensive production function, evaluated at the steady state $(K, a)=(1,1)$, is smaller than one half:

Assumption $3 s<1 / 2$.

As when $\beta=0, s$ represents the capital share in income, Assumption 3 is in accordance with empirical results.

To analyse local stability, we choose $\varepsilon_{\gamma} \in(1,+\infty)$ as the bifurcation parameter. Recalling that the elasticity of labor supply is defined by $1 /\left(\varepsilon_{\gamma}-\right.$ 1 ), it is inversely related to the bifurcation parameter. In particular, labor supply is infinitely elastic when $\varepsilon_{\gamma}$ tends to 1 and the elasticity of labor supply tends to 0 when $\varepsilon_{\gamma}$ tends to $+\infty$. From equations (29) and (30), we notice that, when $\varepsilon_{\gamma}$ varies in $(1,+\infty),(T, D)$ describes a half-line $\Delta$ that can be defined in the plane by:

$$
D=S\left(T-T_{1}\right)+D_{1}, \text { with } S=s(\beta+1 / \sigma)>0
$$

When $\varepsilon_{\gamma}$ tends to its lower bound 1 , the half-line $\Delta$ starts in $\left(T_{1}, D_{1}\right)$. Increasing the bifurcation parameter $\varepsilon_{\gamma}, T$ and $D$ raise along a line with a slope $S$ and tend both to $+\infty$. Therefore, knowing the position of the starting point $\left(T_{1}, D_{1}\right)$ and the level of the slope $S$, we will be able to deduce the position of $(T, D)$ in the plane and therefore, the stability properties of the steady state and the occurrence of bifurcations.

From direct inspection of equation (29), we easily deduce that under Assumption $3, D_{1}$ belongs to $(0,1)$. We also notice that $T_{1}$ and $S$ depend both on $\beta$.

For further reference, we begin by analyzing briefly the case without taste for variety, i.e. $\beta=0$ (see Figure 1). Using equation (30), we deduce that

\footnotetext{
${ }^{15}$ For further information about local bifurcation theory, see for instance Grandmont (1988) or Wiggins (1990).

${ }^{16}$ For more details, see Guesnerie and Woodford (1992) and Grandmont, Pintus, and de Vilder (1998).
} 
$T_{1}=1+D_{1}$, i.e. the starting point $\left(T_{1}, D_{1}\right)$ is on the line $(A C)$ between the horizontal axis and the point $C$. Moreover, the slope $S$ becomes $s / \sigma$, decreasing from $+\infty$ to 0 when $\sigma$ increases from 0 to $+\infty$. Therefore, when $\varepsilon_{\gamma}$ increases from 1, two cases can arise. When $S>1(\sigma<s)$, the halfline $\Delta$ is above $(A C)$, i.e. $(T, D)$ goes inside $(A B C)$ and crosses $[B C]$ for $\epsilon_{\gamma}=(1-s) / s \equiv \epsilon_{\gamma_{H}}{ }^{17}$ On the contrary, when $S \in(0,1)(\sigma>s), \Delta$ is below $(A C)$.

We deduce that the steady state is locally indeterminate and deterministic periodic or quasi-periodic trajectories can occur only if the elasticity of capital-labor substitution is sufficiently weak, i.e. $\sigma<s$. This result is similar to Reichlin (1986) who considers the same overlapping generations model but with perfect competition. ${ }^{18}$ Accordingly, imperfect competition has no role on local dynamics through the level of increasing returns or mark-up. ${ }^{19}$ Indeed, neither the fixed cost $\phi$ nor the mark-up factor $\epsilon /(\epsilon-1)$ appear in the trace $T$ and the determinant $D$ (see equations (29) and (30)).

We turn now to the situation where consumers have taste for variety $(\beta>$ 0 ) and show that endogenous fluctuations can emerge under less restrictive conditions. To simplify the presentation of the results and to be as short as possible, we exclude arbitrarily high degrees of taste for variety ${ }^{20}$ :

Assumption $40<\beta<1-2 s$.

In other words, we introduce taste for variety, but we restrict our analysis to the case where its degree $\beta$ cannot be too great. ${ }^{21}$

To determine the conditions for the occurrence of endogenous fluctuations, we need to analyze, as before, the slope $S$ of the half-line $\Delta$, the location of $\left(T_{1}, D_{1}\right)$ in the plane $(T, D)$, and how they vary when $\sigma$ describes $(0,+\infty)$.

As in the case without taste for variety, the slope $S$ is a decreasing function of $\sigma$, but now from $+\infty$ to $s \beta$. In particular, $S=1$ for $\sigma=\sigma_{T}$, with:

$$
\sigma_{T} \equiv s /(1-s \beta)
$$

${ }^{17}$ The critical value $\epsilon_{\gamma_{H}}$ is defined by $D=1$, or equivalently, by $\epsilon_{\gamma}=1 / D_{1}$.

${ }^{18}$ One can also find a recent presentation of this result in Cazzavillan (2001).

${ }^{19}$ Dos Santos Ferreira and Lloyd-Braga (2005) have also shown that, under a constant mark-up factor, imperfect competition has no role on the emergence of endogenous fluctuations in overlapping generations economies. In contrast to our analysis, they consider no free entry and they need to assume that (positive) profits have no influence on dynamics.

${ }^{20}$ In fact, one can prove that, for higher levels of taste for variety, the conditions for local indeterminacy are not significantly altered when $\sigma$ is not too weak, which is the most interesting case.

${ }^{21}$ For instance, if $s=1 / 3, \beta$ belongs to $(0,1 / 3)$. 


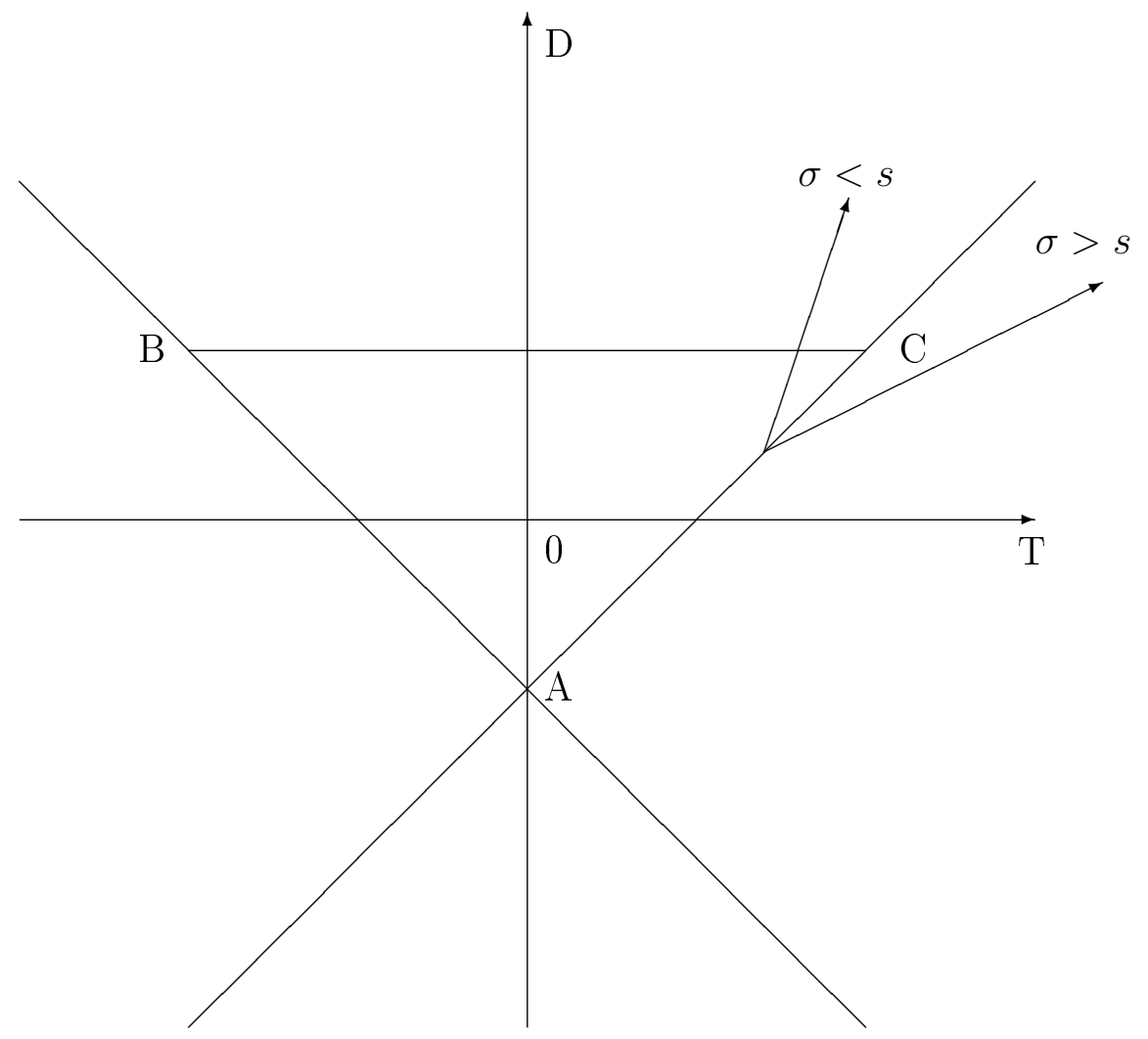

Figure 1: No Taste for Variety $(\beta=0)$

Note that under Assumptions 3 and $4, \sigma_{T}$ belongs to $(0,1 / 2)$. Concerning now the location of $\left(T_{1}, D_{1}\right)$, the only difference concerns $T_{1}$, that decreases with $\sigma$ when $\beta>0$. Using equations (29) and (30), we deduce that when $\sigma$ increases, $\left(T_{1}, D_{1}\right)$ describes an horizontal segment that starts on the right side of the line $(A C)$. Indeed, for $\sigma=0$ and under Assumption 4, we have:

$$
\begin{aligned}
& T_{1}=(\beta+1) /(1-s) \in(1,2) \\
& 1-T_{1}+D_{1}=-\beta /(1-s)<0
\end{aligned}
$$

When $\sigma$ increases, $\left(T_{1}, D_{1}\right)$ goes leftward, crossing the line $(A C)$ for $\sigma=$ $1 / 2$ and being inside $(A B C)$ for all $\sigma>1 / 2$. In the limit case where $\sigma$ tends to $+\infty,\left(T_{1}, D_{1}\right)$ is on the line $(A B)$ :

$$
T_{1}=-1 /(1-s) \text { and } 1+T_{1}+D_{1}=0
$$

We deduce from these features (see also Figure 2) that for $\sigma$ sufficiently close to 0 , the half-line $\Delta$, starting below $(A C)$, crosses this line below the 
point $C$ for $\varepsilon_{\gamma}=\varepsilon_{\gamma_{T}},{ }^{22}$ goes inside $(A B C)$ and crosses the segment $[B C]$ for $\varepsilon_{\gamma}=\varepsilon_{\gamma_{H}} \cdot{ }^{23}$ Recall now that, following an increase of $\sigma, S$ decreases and $\left(T_{1}, D_{1}\right)$ goes leftward, and there is a critical value $\sigma_{T}(<1 / 2)$ such that $S=1,\left(T_{1}, D_{1}\right)$ staying on the right side of $(A C)$. By continuity, there exists $\sigma_{H} \in\left(0, \sigma_{T}\right)$ such that the half-line $\Delta$ goes through point $C .{ }^{24}$ Therefore, when $\sigma_{H}<\sigma<\sigma_{T}, \Delta$ starts below $(A C)$ and only crosses this line above the point $C$. When $\sigma_{T} \leq \sigma \leq 1 / 2$, the slope of the half-line $\Delta$ becomes smaller than one and $\left(T_{1}, D_{1}\right)$ is always on the right side of $(A C)$. Then, $\Delta$ is below the line $(A C)$. When $\sigma>1 / 2,\left(T_{1}, D_{1}\right)$ is now inside $(A B C)$ and the half-line $\Delta$ only crosses the line $(A C)$ below the point $C .{ }^{25}$

These results can be summarized in the following proposition (see also Figure 2):

Proposition 3 If inequality (28) and Assumptions 1-4 are satisfied, the following generically holds.

1. When $0<\sigma<\sigma_{H}$, the steady state is a saddle for $\varepsilon_{\gamma}<\varepsilon_{\gamma_{T}}$, undergoes a transcritical bifurcation for $\varepsilon_{\gamma}=\varepsilon_{\gamma_{T}}$, becoming a sink for $\varepsilon_{\gamma_{T}}<\varepsilon_{\gamma}<$ $\varepsilon_{\gamma_{H}}$, undergoes a Hopf bifurcation for $\varepsilon_{\gamma}=\varepsilon_{\gamma_{H}}$, becoming a source for $\varepsilon_{\gamma}>\varepsilon_{\gamma_{H}}$

2. When $\sigma_{H}<\sigma<\sigma_{T}$, the steady state is a saddle for $\varepsilon_{\gamma}<\varepsilon_{\gamma_{T}}$, undergoes a transcritical bifurcation for $\varepsilon_{\gamma}=\varepsilon_{\gamma_{T}}$, becoming a source for $\varepsilon_{\gamma}>\varepsilon_{\gamma_{T}}$;

3. When $\sigma_{T} \leq \sigma \leq 1 / 2$, the steady state is always a saddle;

4. When $\sigma>1 / 2$, the steady state is a sink for $\varepsilon_{\gamma}<\varepsilon_{\gamma_{T}}$, undergoes a transcritical bifurcation for $\varepsilon_{\gamma}=\varepsilon_{\gamma_{T}}$, becoming a saddle for $\varepsilon_{\gamma}>\varepsilon_{\gamma_{T}}$.

The critical values $\sigma_{H}, \sigma_{T}, \varepsilon_{\gamma_{H}}$ and $\varepsilon_{\gamma_{T}}$ are given by:

$$
\begin{aligned}
& \sigma_{H}=s(1-2 s-\beta) /[1-2 s-\beta s(3-2 s)], \sigma_{T}=s /(1-s \beta), \\
& \varepsilon_{\gamma_{H}}=(1-s) / s \text { and } \varepsilon_{\gamma_{T}}=1+(2 \sigma-1) \beta /[\sigma(1-\beta s)-s]
\end{aligned}
$$

\footnotetext{
${ }^{22}$ The value $\varepsilon_{\gamma_{T}}$ is defined by $1-T+D=0$. Using (29) and (30), we obtain $\varepsilon_{\gamma_{T}}=$ $1+(2 \sigma-1) \beta /(\sigma-s-\beta \sigma s)$.

${ }^{23} \mathrm{As}$ in the case without taste for variety, $\varepsilon_{\gamma_{H}}=(1-s) / s$ is defined by $D=1$.

${ }^{24}$ The critical value $\sigma_{H}$ is defined by $D=1$ and $T=2$. Using (29) and (30), we obtain $\sigma_{H} \equiv s(1-2 s-\beta) /[1-2 s-\beta s(3-2 s)]$.

${ }^{25}$ Since the slope $S$ decreases and $\left(T_{1}, D_{1}\right)$ goes leftward when $\sigma$ increases, one cannot exclude a priori that $\Delta$ crosses the point $C$ when $\sigma>1 / 2$. However, one can easily prove that, under Assumptions 3 and $4, \varepsilon_{\gamma_{H}}>\varepsilon_{\gamma_{T}}$ for all $\sigma>1 / 2$, showing that the half-line $\Delta$ always goes below the point $C$.
} 


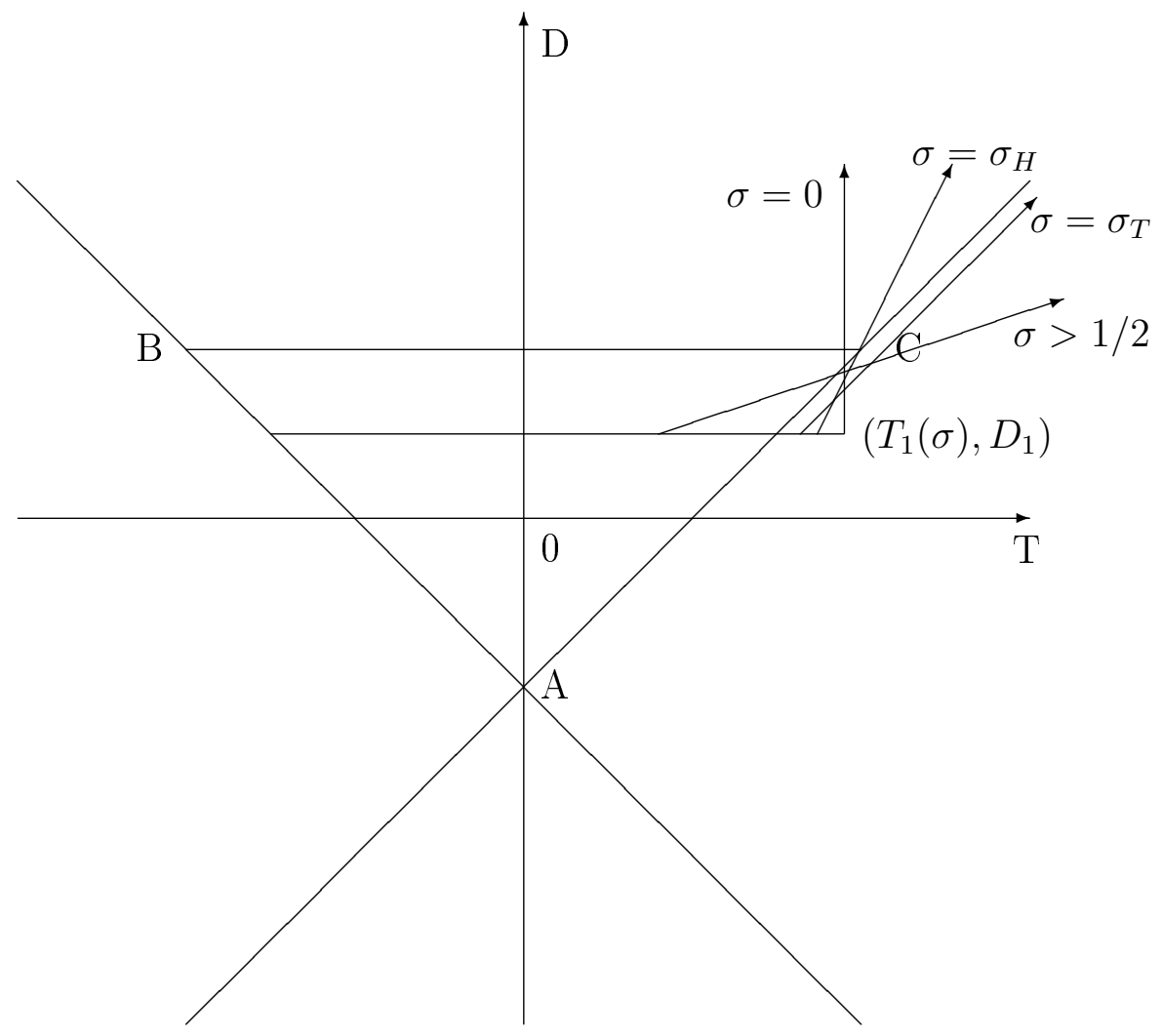

Figure 2: $1-2 s>\beta>0$

This proposition shows that deterministic fluctuations can appear only if capital and labor are weak substitutes $\left(0<\sigma<\sigma_{H}\right)$. In this case, we also notice that the steady state can be locally indeterminate, i.e. fluctuations driven by the volatility of expectations can occur. This first result is quite similar to the one obtained without taste for variety. Note however that $\sigma_{H}$ is smaller than $s .{ }^{26}$ But now local indeterminacy can also arise for all $\sigma>1 / 2$, i.e. when capital and labor are higher substitutes. Hence, fluctuations due to self-fulfilling prophecies can emerge for values of the elasticity of capitallabor substitution in accordance with recent empirical studies (Duffy and Papageorgiou (2000)), even if the degree of taste for variety is not too large (Assumption 4).

Imperfect competition has an influence on local indeterminacy and the occurrence of bifurcations only through taste for variety. ${ }^{27}$ As we have al-

\footnotetext{
${ }^{26}$ By direct inspection of $\sigma_{H}$ (see Proposition 3 ), one notes that this critical value decreases from $s$ to 0 when $\beta$ grows from 0 to $1-2 s$.

${ }^{27}$ The inherent economic mechanism will be explained later.
} 
ready explained, the level of mark-up $\epsilon /(\epsilon-1)$ and the fixed cost $\phi$ have no role on local dynamics. We can also conclude that the fixed cost $\phi$ can be low and even close to zero, that is, increasing returns can be arbitrarily close to constant returns. This seems to be in accordance with empirical studies (Basu and Fernald (1995), Basu and Fernald (1997), Burnside (1996)) which establish that if returns to scale are increasing, they are not far from constant returns.

Finally notice that when capital and labor are not weak substitutes $(\sigma>1 / 2)$, endogenous fluctuations emerge for $\varepsilon_{\gamma}<\varepsilon_{\gamma_{T}}$, that is, an elasticity of labor supply greater than $1 /\left(\varepsilon_{\gamma_{T}}-1\right)$. One can immediately see that even if increasing returns are arbitrarily close to the constant ones, local indeterminacy does not require an infinitely elastic labor supply. Indeed, recall that $\beta<1-2 s$ and consider for instance that the technology is Cobb-Douglas $(\sigma=1)$ and $s=1 / 3 .^{28}$ Then, endogenous fluctuations occur if the elasticity of labor supply is greater than $5 / 3$. This lower bound is more in accordance with empirical findings (Pencavel (1986), Killingsworth and Heckman (1986), Blundell and Macurdy (1999)). However, by direct inspection of the expression of $\varepsilon_{\gamma_{T}}$ (see Proposition 3), we remark that when taste for variety becomes arbitrarily small, indeterminacy requires an almost infinitely elastic labor supply for $\sigma>1 / 2$.

Before providing concluding remarks, it is important to notice that the results obtained in this paper depart from the perfectly competitive case because with taste for variety, the real wage and the real interest rate are no more equal to the marginal productivities of labor and capital, but a same variable distortion affects the real prices of production factors. ${ }^{29}$ The existence of such a variable distortion can be explained as follows: when consumers have taste for variety, the aggregate price is no more equal to the price of each variety of good, but decreases with respect to the pro-cyclical number of firms. As a consequence, following an increase of current labor and/or capital, there is an adding effect on real wage and real interest rate. The product diversity will increase, which will have a negative effect on the aggregate price and finally, a positive one on the real wage and interest rate.

\section{Conclusion}

This work shows that imperfect competition affects the emergence of endogenous fluctuations not only because of the existence of increasing returns to

\footnotetext{
${ }^{28}$ This parametrization is often used in macroeconomic dynamic models.

${ }^{29}$ Note that part of this distortion $(1-1 / \epsilon)$ is constant and comes from the existence of a fixed mark-up.
} 
scale (decreasing marginal cost), mark-up variability or monopoly profits, as already stressed by some economists, but also through taste for variety. Indeed, introducing monopolistic competition (Dixit and Stiglitz (1977), Benassy (1996)) in an overlapping generations economy where consumers have taste for variety, we prove that local indeterminacy can occur when capital and labor are not weak substitutes, increasing returns are arbitrarily small and labor supply is not too elastic. The new mechanism that operates in this paper is the following: with taste for variety, the pro-cyclical product diversity has a negative effect on the aggregate price, and therefore, a positive one on the the real wage and the real interest rate.

\section{Appendix}

\section{Proof of Proposition 2}

We substitute explicitly equations (15), (16) and (21) into (22) and (23). Then, we differentiate the dynamic system obtained using the elasticities (19) and (20). With the notations $s \equiv s(1), \sigma \equiv \sigma(1)$ and $\varepsilon_{\gamma} \equiv \varepsilon_{\gamma}(1)$, we get:

$$
\begin{gathered}
\frac{d K_{t}}{K}=(1+\beta) \frac{d K_{t-1}}{K}-[1+(1-s) \beta-s / \sigma] \frac{d a_{t}}{a} \\
\frac{d a_{t+1}}{a}=\frac{\beta(2+\beta)-\left(\varepsilon_{\gamma}-1\right)}{(1-s)(\beta+1 / \sigma)} \frac{d K_{t-1}}{K} \\
+\frac{\varepsilon_{\gamma}-1-\beta[1+(1-s)(1+\beta)]+(1+\beta) s / \sigma}{(1-s)(\beta+1 / \sigma)} \frac{d a_{t}}{a}
\end{gathered}
$$

Since $T$ and $D$ represent respectively the trace and the determinant of the associated Jacobian matrix, Proposition 2 immediately follows.

\section{References}

Ball, L., And D. Romer (1991): "Sticky Prices as Coordination Failure," American Economic Review, 81, 539-552.

BAsu, S., AND J. Fernald (1995): "Are Apparent Productive Spillovers a Figment of Specification Error ?," Journal of Monetary Economics, 36, $165-188$.

(1997): "Returns to Scale in US Production: Estimates and Implications," Journal of Political Economy, 105, 249-283. 
Benassy, J.-P. (1996): "Taste for Variety and Optimum Production Patterns in Monopolistic Competition," Economics Letters, 52, 41-47.

Benhabib, J., and R. E. A. FArmer (1994): "Indeterminacy and Increasing Returns," Journal of Economic Theory, 63, 19-41.

Blundell, R., And T. Macurdy (1999): "Labor Supply: a Review of Alternative Approaches," in Handbook of Labor Economics, ed. by O. Ashenfelter, and D. Card, pp. 1559-1695, Amsterdam. North-Holland.

Burnside, C. (1996): "Production Function Regressions, Returns to Scale, and Externalities," Journal of Monetary Economics, 37, 177-201.

Cazzavillan, G. (2001): "Indeterminacy and Endogenous Fluctuations with Arbitrarily Small Externalities," Journal of Economic Theory, 101, $133-157$.

Cazzavillan, G., T. Lloyd-Braga, and P. Pintus (1998): "Multiple Steady States and Endogenous Fluctuations with Increasing Returns to Scale in Production," Journal of Economic Theory, 80, 60-107.

Cook, D. (2001): "Time to Enter and Business Cycles," Journal of Economic Dynamics and Control, 25, 1241-1261.

Dixit, A., And J. Stiglitz (1977): "Monopolistic Competition and Optimum Product Diversity," American Economic Review, 67, 297-308.

Dos Santos Ferreira, R., And T. Lloyd-Braga (2002): "Can Market Power Sustain Endogenous Growth in Overlapping-generations Economies?," Economic Theory, 20, 199-205.

(2005): "Nonlinear Endogenous Fluctuations with Free Entry and Variable Markups," Journal of Economic Dynamics and Control, 29, 849871.

Duffy, J., And C. PApageorgiou (2000): "A Cross-country Empirical Investigation of the Aggregate Production Function Specification," Journal of Economic Growth, 5, 87-120.

Gali, J. (1994): "Monopolistic Competition, Business Cycles, and the Composition of Aggregate Demand," Journal of Economic Theory, 63, 73-96.

Grandmont, J.-M. (1988): "Nonlinear Difference Equations, Bifurcation and Chaos: an Introduction," Working Paper 8811, CEPREMAP. 
Grandmont, J.-M., P. Pintus, and R. DE Vilder (1998): "Capitallabour Substitution and Competitive Nonlinear Endogenous Business Cycles," Journal of Economic Theory, 80, 14-59.

Guesnerie, R., And M. Woodford (1992): "Endogenous Fluctuations," in Advances in Economic Theory: Proceedings of the $6^{\text {th }}$ World Congress of the Econometric Society, ed. by J.-J. Laffont, vol. 2, pp. 289-412, Cambridge, Ma. Cambridge University Press.

Jacobsen, H. J. (1998): "Endogenous Product Diversity and Endogenous Business Cycles," Discussion Paper 98-15, University of Copenhagen.

(2000): "Endogenous, Imperfectly Competitive Business Cycles," European Economic Review, 44, 305-336.

Killingsworth, M., and J. Heckman (1986): "Female Labor Supply: a Survey," in Handbook of Labor Economics, ed. by O. Ashenfelter, and R. Layard, pp. 103-204, Amsterdam. North-Holland.

KIYotaki, N. (1988): "Multiple Expectational Equilibria under Monopolistic Competition," Quaterly Journal of Economics, 103, 695-714.

Lloyd-BragA, T. (1995): "Increasing Returns to Scale and Endogenous Fluctuations," Working Paper 65/95, Universidade Católica Portuguesa.

Lloyd-Braga, T., C. Nourry, and A. Venditti (2006): "Indeterminacy in Dynamic Models: When Diamond Meets Ramsey," Journal of Economic Theory, in press.

Nourry, C., And A. VenditTi (2006): "The OLG Model with Endogenous Labor Supply: a General Formulation," Journal of Optimization Theory and Applications, 128, 355-377.

Pencavel, J. (1986): "Labor Supply of Men: a Survey," in Handbook of Labor Economics, ed. by O. Ashenfelter, and R. Layard, pp. 3-102, Amsterdam. North-Holland.

Reichlin, P. (1986): "Equilibrium Cycles in an Overlapping Generations Economy with Production," Journal of Economic Theory, 40, 89-103.

Rivard, B. (1994): "Monopolistic Competition, Increasing Returns, and Self-fulfilling Prophecies," Journal of Economic Theory, 62, 346-362. 
Seegmuller, T. (2004): "Capital-labor Substitution and Endogenous Fluctuations: a Monopolistic Competition Approach with Variable Mark-up," miméo, Paris.

(2005): "On the Stabilizing Virtues of Imperfect Competition," International Journal of Economic Theory, 1, 313-323.

Weder, M. (2000): "Animal Spirits, Technology Shocks and the Business Cycle," Journal of Economic Dynamics and Control, 24, 273-295.

Wiggins, S. (1990): Introduction to Applied Nonlinear Dynamical Systems and Chaos. Springer-Verlag, New-York. 